\title{
Biosorption and Chemical Precipitation of Lead Using Biomaterials, Molecular Sieves, and Chlorides, Carbonates, and Sulfates of Na \& Ca
}

\section{Lovell Agwaramgbo ${ }^{*}$, Nancy Magee, ShaKayla Nunez, Kayla Mitt}

Chemistry Department, School of Science, Technology, Engineering, and Mathematics, Dillard University, New Orleans, USA.

Email: *lagwaramgbo@dillard.edu

Received August $10^{\text {th }}, 2013$; revised September $11^{\text {th }}, 2013$; accepted October $13^{\text {th }}, 2013$

Copyright (c) 2013 Lovell Agwaramgbo et al. This is an open access article distributed under the Creative Commons Attribution License, which permits unrestricted use, distribution, and reproduction in any medium, provided the original work is properly cited.

\begin{abstract}
Lead, a heavy metal, is a well known contaminant in water and has been reported to cause serious health implications to humans, animals, and plants. One of the processes for heavy metal remediation of contaminated water is chemical precipitation. In this present work, chemical precipitation of lead from a contaminated aqueous matrix by chlorides, carbonates, and sulfates of sodium and calcium was compared to lead removal by molecular sieves and biomaterials (fishbone, grape and spinach). The order of lead removal from $1400 \mathrm{ppm}$ of lead solution is sodium chloride $(31 \%)<$ calcium chloride $(62 \%)<$ burnt grape $(83 \%)<$ charred spinach $(92.3 \%)<$ sodium phosphate $(95.8 \%)<$ sodium carbonate $(97 \%)<$ molecular sieve sphere $(98.7 \%)<$ sodium sulfate $(99.3 \%)<$ calcium sulfate $(99.7 \%)<$ molecular sieves ground $(99.71 \%)<$ fishbone $(99.87 \%)<$ calcium carbonate $(99.9 \%)$.
\end{abstract}

Keywords: Heavy Metals; Chemisorption; Biochar; Fishbone; Molecular Sieves; Bioremediation; Precipitation

\section{Introduction}

Heavy metal contamination, especially lead, has been a constant common problem worldwide [1]. Military firing ranges, ammunition manufacturing facilities, agricultural and waste disposal practices, mining industries and other industrial processes are major sources of these hazardous heavy metals. Chronic exposure to these heavy metals poses a major threat to soil, water, and food safety because of their inherent toxicity to living organisms, especially humans [2]. Several methods that have been proposed for the removal of these heavy metals from the soil, and water include adsorption and chemical precipitation [3-7], Lime treatment [8], ion exchange [9,10], extraction [11] and a host of other techniques delineated in Zvinowanda's paper [12]. In as much as these methods which have great potential for heavy metal remediation, they are expensive and they (a) require large amount of reagents (b) generate large volumes of reagents and (c) need further treatment of their waste and (d) may lead to incomplete mitigation and expensive waste disposal. Although use of activated carbon in separation has been practiced for cen-

${ }^{*}$ Corresponding author. turies, its use in heavy metal remediation has been greatly explored recently [13-18].

Recent research studies have reported the use of biomaterials such as apatite $[4,5,12]$, chitosan $[13,14]$, rice hulls, dead biomass, crab shell, bark, coconut fiber [15], soil, fruits and vegetables, and fishbone [18-21], seed powder [22], and woodchar [23] in heavy metal remediation. Similarly, there is a growing research interest in the use of some micro-porous materials such as zeolites in heavy metal remediation [24-28]. The study reported here compares chemical precipitation or adsorption of lead from contaminated aqueous solution by commercial chemicals (chlorides, carbonates, and sulfates of sodium and calcium) and biomaterials (Charred grapes and spinach, fishbone) and molecular sieves.

\section{Materials \& Methods}

The lead nitrate was purchases from Fisher Scientific while sodium chloride, sodium carbonate, sodium sulfate, sodium hydrogen phosphate, calcium chloride, calcium carbonate, calcium sulfate and molecular sieves (spheres, 8 12 mesh) were purchased from Aldrich Chemicals and 
were used without further purification. Fishbone was obtained from stockfish bought from Norway. Grape and spinach were bought from local Wal-Mart store.

\subsection{Preparation of Lead Nitrate Solution 1400 ppm}

Using an analytical balance, $1.4 \mathrm{~g}$ of lead Nitrate from Fisher Scientific (L6200) was dissolved in enough deionized water (added incrementally) to give $1000 \mathrm{ml}$ of solution. Then a stirring bar was dropped into the volumetric flask and the mixture was stirred until all the lead was completely dissolved. The flask was wrapped with aluminum foil to avoid much exposure to light while the solution continued to stir at room temperature until it was used.

\subsection{Preparation of the Chloride, Carbonate, and Sulfate Salts of Sodium and Calcium and Sodium Phosphates}

Triplicate $4 \mathrm{~g}$ samples of each of these sodium and calcium salts were weighed in separate $50 \mathrm{ml}$ centrifuge tubes, respectively for each salt. Each tube was labeled accordingly.

\subsection{Preparation of Charred Grape and Spinach}

Separate triplicate $4.0 \mathrm{~g}$ samples of ground charred grape and spinach (heated in a metal wire basket in an oven until charred, then ground into fine powder and sieved with a $500 \mu \mathrm{m}$ sieve) were weighed into their respective $50 \mathrm{ml}$ centrifuge tubes labeled CCG and CCSP

\subsection{Preparation of Stockfish Bone Substrate}

Six-3ft dried stockfish from Norway were bought from a local market, deboned after soaking in water at room temperature for $3 \mathrm{hr}$. The bones were washed with deionized water and dried in an oven at $50^{\circ} \mathrm{C}$ for $24 \mathrm{hr}$. The dried bones were pulverized using a blender and sieved with $500 \mu \mathrm{m}$ sieve. Three $50-\mathrm{ml}$ centrifuge tubes were charged with $4.0 \mathrm{~g}$ of the fishbone respectively. The tubes were labeled FB-S.

\subsection{Reaction of the Substrates with Lead}

Into each of the respective triplicate centrifuge tubes containing the substrates was added $40 \mathrm{ml}$ of $1400 \mathrm{ppm}$ of lead nitrate solution prepared above. The tubes and their contents were vortexed, secured tightly on a heavy duty Eberbach 6000 shaker, and agitated for $48 \mathrm{hr}$ at room temperature.

\subsection{Sample Preparation and Analysis}

\section{Sample Preparation}

After $48 \mathrm{hrs}$, the shaker was stopped and the centrifuge tubes and their contents were centrifuged at $3000 \mathbf{~ r p m}$ for ten minutes. The resulting supernatant in each tube was respectively transferred into another labeled clean centrifuge tube. All the labeled centrifuge tubes with their liquid contents were sent to PACE Analytical Services, Inc for lead analysis using EPA method 6010.

\subsection{Sample Analysis for Lead after Reaction}

After the reaction period, the lead concentration (in ppm) in the liquid from each reaction tube was analyzed using EPA Method 6010C (Inductively Coupled Plasma-Atomic Emission Spectrometry (ICP-AES)). Note ICP-AES produces emission spectra specific for each element and exploits the fact that excited electrons emit certain amount of energy at various wavelengths as they return to the ground state. The intensity of the emitted energy is proportional to the concentration of the metal in the sample relative to a reference standard.

\section{Results}

Data on Table 1 show residual lead in $\mathbf{p p m}$ in each reaction vessel after contaminated water was treated with each

Table 1. Residual \& removed lead in contaminated water after treatment with substrates.

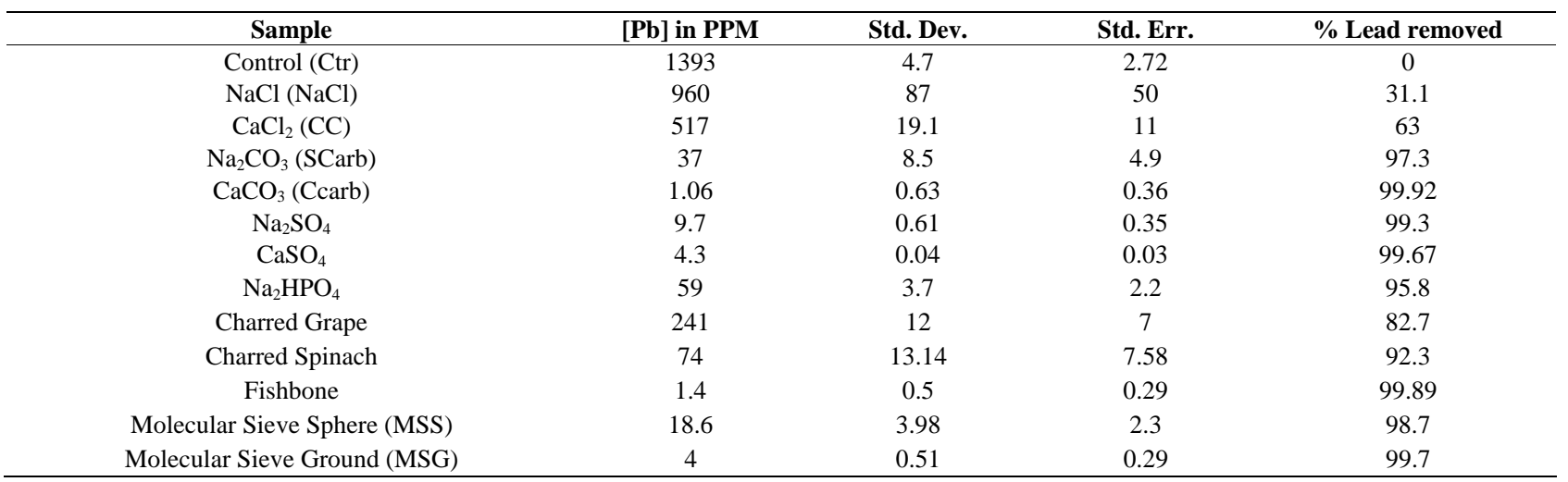


substrate for $48 \mathrm{hrs}$ and the percent of lead removed compared to the control: ctr. (1393, 0\%); sodium chloride (31\%); calcium chloride (63\%); charred grape (83\%); charred spinach (92.3\%); sodium phosphate (95.8\%); sodium carbonate (97\%); molecular sieve sphere (98.7\%); sodium sulfate (99.3\%); calcium sulfate (99.7\%), molecular sieve ground (99.71\%); fishbone (99.87\%); and calcium carbonate (99.9\%).

Figure 1 shows residual lead in the reaction mixture after substrates were agitated with lead solution. Figure 2 shows the amount of lead remaining in the reaction mixture after sodium salts (chloride, carbonate, and sulfate) reacted with the lead solution when compared to the amount remaining in the fishbone reaction and the control while Figure 3 shows the amount of lead remaining in the reaction mixture after calcium salts (chloride, carbonate, and sulfate) reacted with the lead solution. Figure 4 compares the residual lead after the reaction of lead solution with sodium and calcium salts.

\section{Discussions}

The results on Table 1 and Figures 1-4 showed that for each class of salt, the calcium salts removed more lead from contaminated water than the corresponding sodium salts. Furthermore, the data showed that of all the sub- strates, calcium carbonate had the highest percent of lead removal from contaminated water (99.92\%). Figures 5 and 6 revealed that Fishbone was very effective in removing lead surpassing all substrates, except calcium carbonate. Those figures also showed that ground molecular sieve removed more lead than molecular sieve spheres, suggesting the influence of particle size or surface area in sorption efficiency of solid substrates. This is in agreement with the findings by Aliabadi et al. on the effect of particle size on chromium adsorption where 20 30 mesh lignocellulosic solid waste adsorbed more chromium than the corresponding 30 - 50 mesh substrate [28]. Of the biomaterials, charred spinach and grape removed less lead than molecular sieves and calcium salts (carbonates and sulfates) except for calcium chloride. This could be attributed in part to the fact that during the heating in the charring process, their tannin poly-phenols or phytochemical components decomposed, evaporated or denatured. This temperature effect on substrate's lead removal potential has been reported by Agwaramgbo et al. [19, 20].

\section{Conclusion}

Calcium salts (chlorides, sulfates, and carbonates) are better lead precipitators than the corresponding sodium salts.

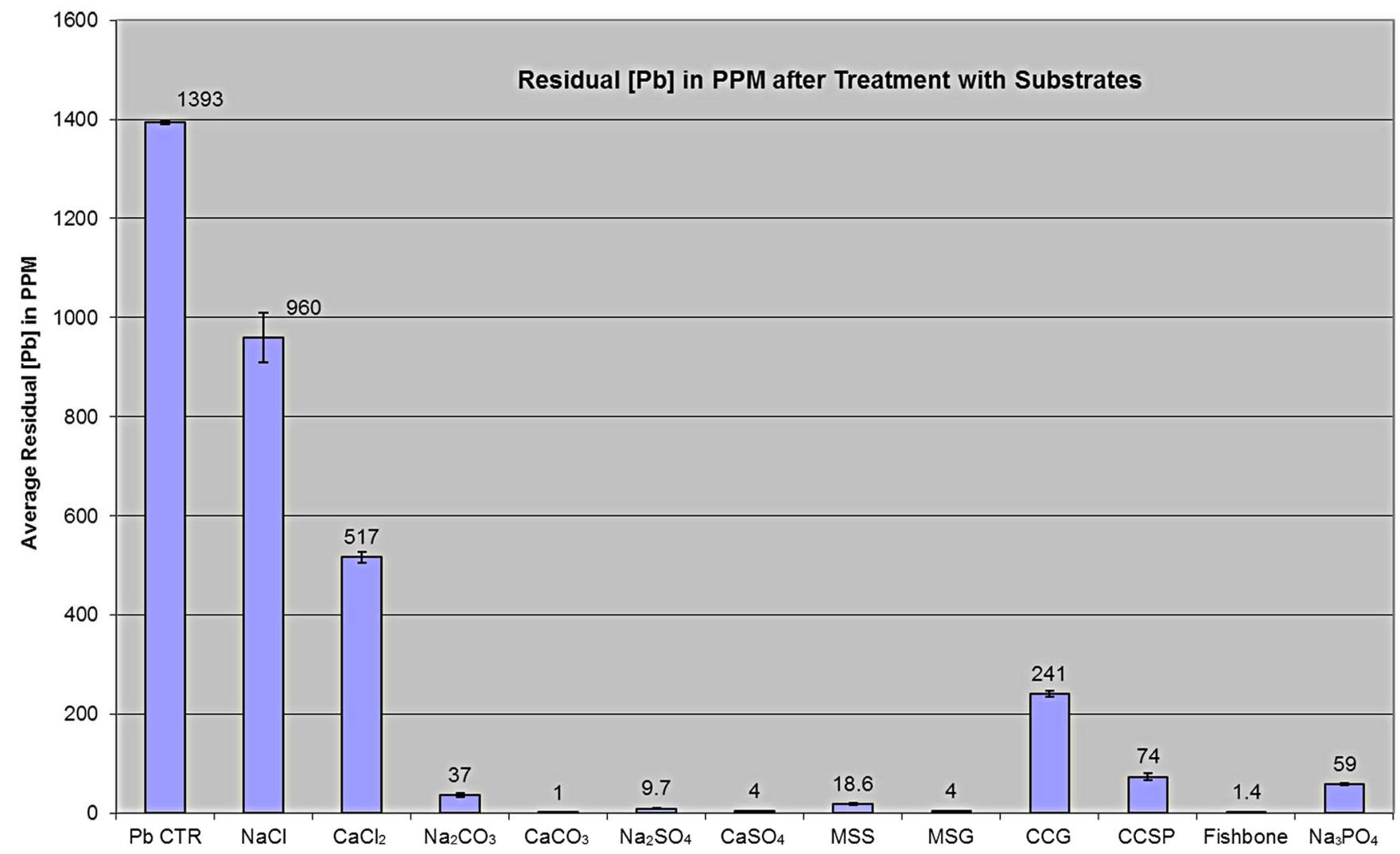

Figure 1. Residual \& removed lead in contaminated water after treatment with substrates. 


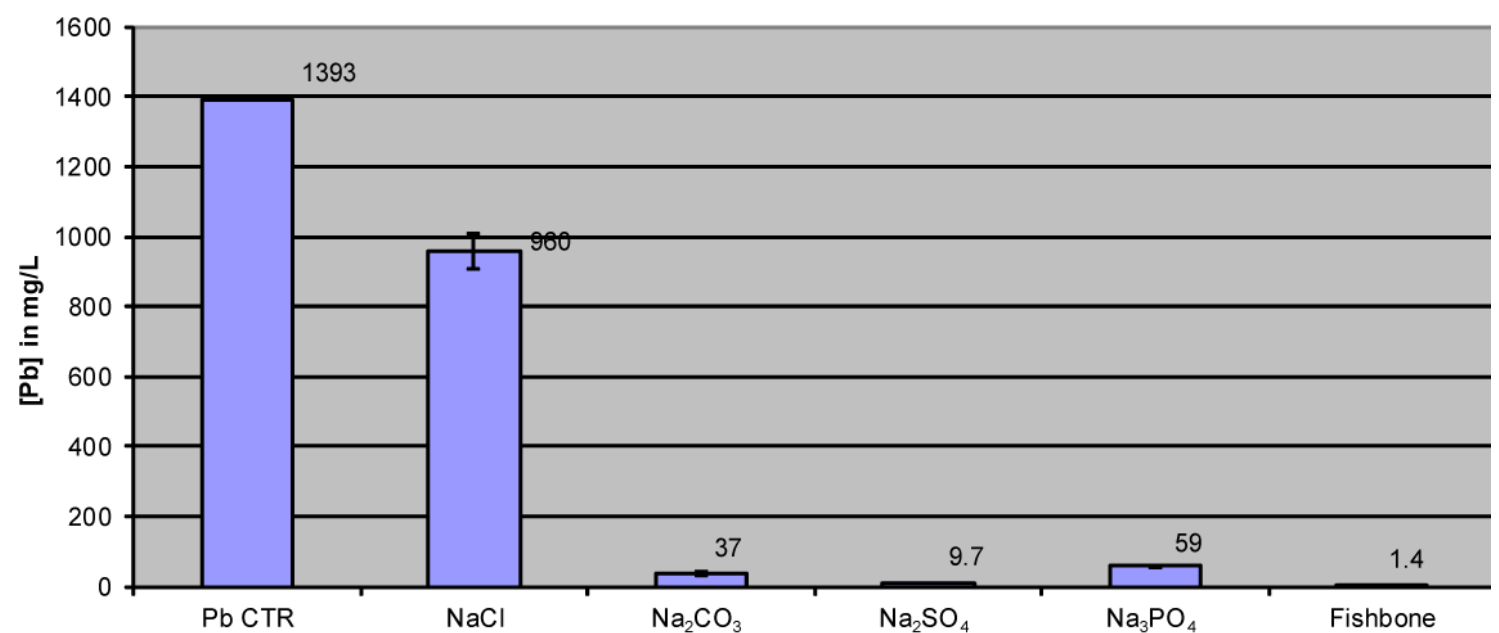

Figure 2. Residual lead concentration after contaminated water was treated with sodium salts (chloride, carbonate, sulfate, and phosphate) compared to fishbone and lead control.

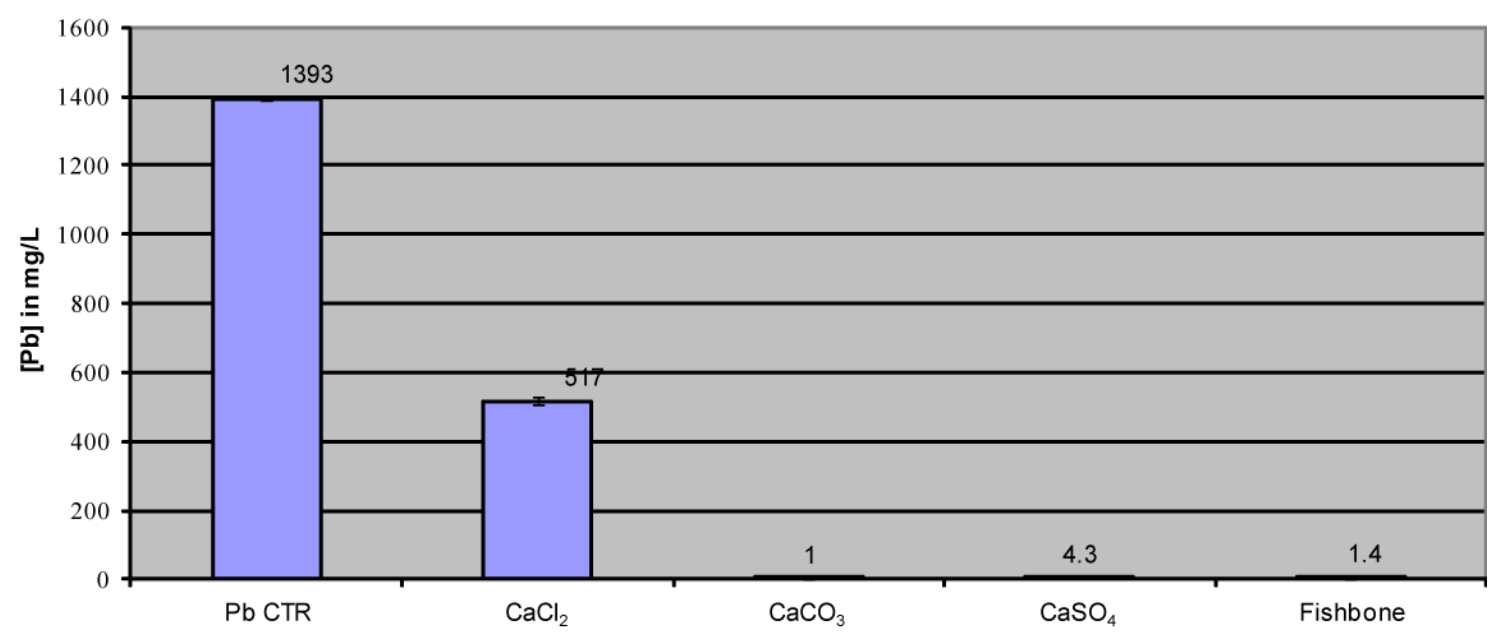

Figure 3. Residual lead concentration after contaminated water was treated with calcium salts (chloride, carbonate, and sulfate compared to fishbone and lead control.

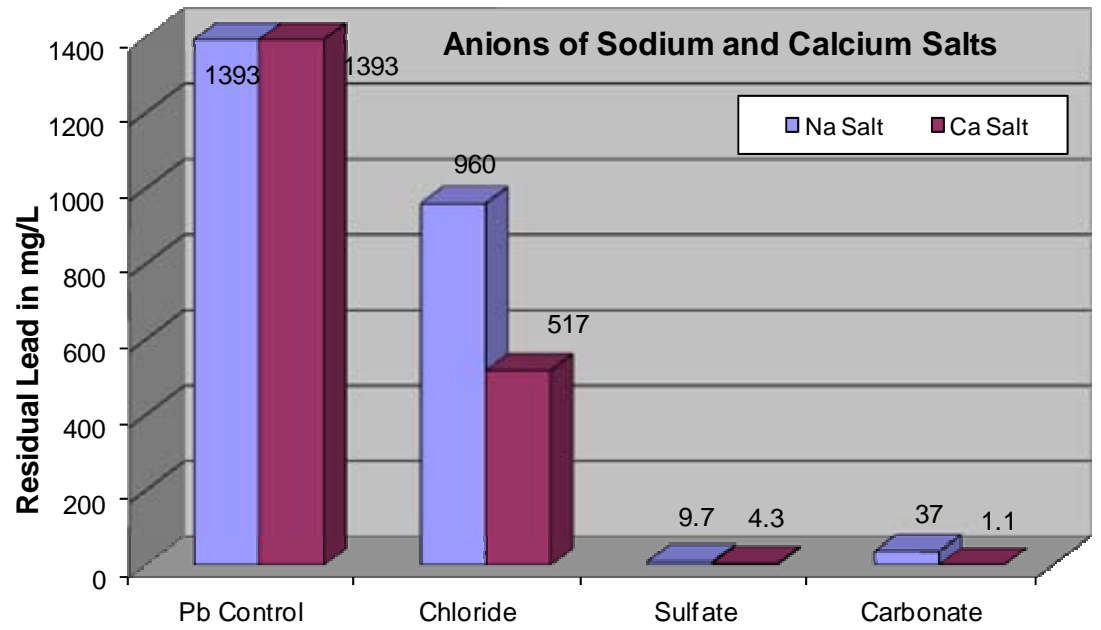

Figure 4. Comparison of residual lead concentration after contaminated water was treated with chlorides, carbonates, and sulfates of sodium and calcium. 


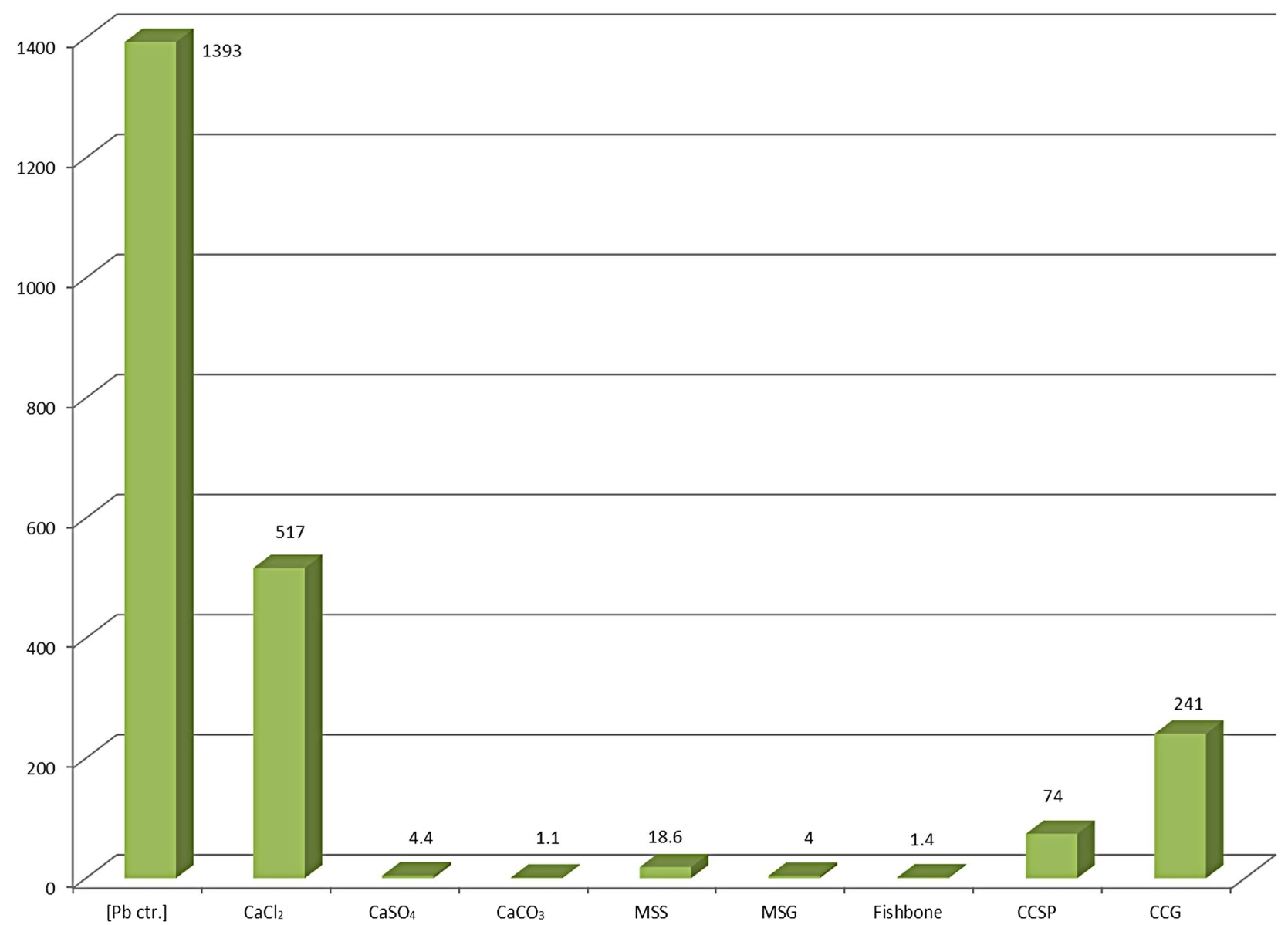

Figure 5. Comparison of residual lead concentration after contaminated water was treated with calcium salts, molecular sieves, and natural biomaterial (fishbone and charred grape and spinach).

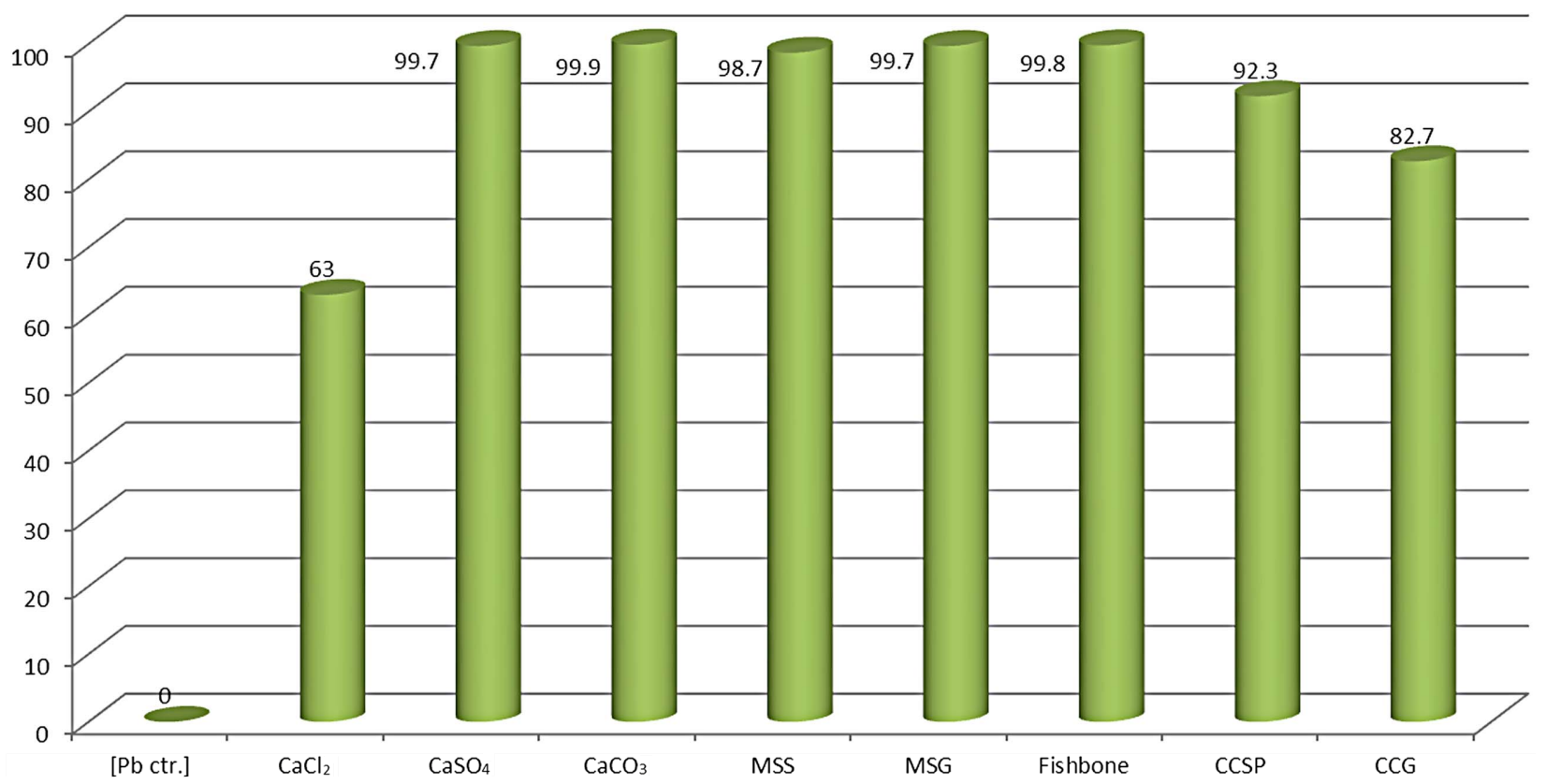

Figure 6. Comparison of percent lead removal by calcium salts, molecular sieves, and natural biomaterial (fishbone and charred grape and spinach). 
Ground molecular sieves adsorbed more lead than the salts of sodium and calcium, except for calcium carbonate. The fact that ground spherical molecular sieves removed more lead than un-ground one suggests that size and surface area affect the efficiency of heavy metal adsorption by solid substrates. Although the biochar (charred spinach and grape) did not remove as much lead as the calcium sulfate and carbonate, yet, they removed a significant amount of lead ranging from $80 \%-92 \%$ lead removal. Additionally, the fact that ground fishbone, another biomaterial, removed more lead than all the commercial chemical substrates, except for calcium carbonate suggests that biomaterials can become viable cheap and safe alternative for the remediation of heavy metals in water and industrial effluents.

\section{REFERENCES}

[1] S. Tong, Y. E. von Schirnding and T. Prapamontol, "Environmental Lead Exposure: A Public Health Problem of Global Dimensions,” Bulletin of the World Health Organization, Vol. 78, No. 9, 2000, pp. 1068-1077.

[2] L. J. Fewtrell, A. Pruss-Ustun, P. Landrigan and J. L. Ayuso-Mateos, "Estimating the Global Burden of Disease of Mild Mental Retardation and Cardiovascular Diseases from Environmental Lead Exposure,” Environmental Research, Vol. 94, No. 2, 2004, pp. 120-133.

http://dx.doi.org/10.1016/S0013-9351(03)00132-4

[3] T. A. Kumiawan, G. Y. S. Chan, W. H. Lo and S. Ba-bel, "Physico-Chemical Treatment Technique for Waste Water Laden with Heavy Metal," Chemical Engineering Journal, Vol. 118, No. 1-2, 2006, pp. 83-98. http://dx.doi.org/10.1016/j.cej.2006.01.015

[4] M. Q. Y. Ma, "Effects of Aqueous Al, Cd, Cu, Fe (II), Ni, and $\mathrm{Zn}$ on $\mathrm{Pb}$ Immobilization by Hydroxyapatite," Environmental Science \& Technology, Vol. 28, No. 7, 1994, pp. 1219-1228.

[5] S. P. Singh, L. Q. Ma and W. G. Harris, "Heavy Metal Interactions with Phosphate Clay: Sorption and Desorption Behavior,” Journal of Environmental Quality, Vol. 30, No. 6, 2001, pp. 1961-1968.

http://dx.doi.org/10.2134/jeq2001.1961

[6] D. Mohan and C. U. Pittman, “Activated Carbons and Low Cost Sorbents for Remediation of Tri- and Hexa-Valent Chromium from Water,” Journal of Hazardous Materials, Vol. B137, No. 2, 2006, pp. 762-811.

http://dx.doi.org/10.1016/j.jhazmat.2006.06.060

[7] T. R. Harper and N. W. Kinham, "Removal of Arsenic from Wastewater Using Chemical Precipitation Methods," Water Environment Research, Vol. 64, No. 3, 1992, pp. 200-203. http://dx.doi.org/10.2175/WER.64.3.2

[8] C. W. Gray, S. J. Dunham, P. G. Dennis, F. J. Zhao and S. P. McGrath, "Field Evaluation of in-Situ Remediation of a Heavy Metal Contaminated Soil Using Lime and RedMud,” Environmental Pollution, Vol. 142, No. 3, 2006, pp. 530-539. http://dx.doi.org/10.1016/j.envpol.2005.10.017

[9] M. B. Mahmood, A. A. Nagham and A. T. Manal, "Removal of Chromium from Electroplating Waste-Water by Simple Chemical Treatment and Ion Exchange," Engineering \& Technology, Vol. 26, No. 11, 2008, pp. 1-9.

[10] R. S. Juang and L. D. Shiau, "Ion Exchange Equilibria of Metal Chelates of Ethylenediaminetetra-Acetic Acid with Amberlitet IRA-68,” Industrial \& Engineering Chemistry Research, Vol. 37, No. 2, 1998, pp. 555-571. http://dx.doi.org/10.1021/ie970519c

[11] R. R. Krishna, C. Y. Xu and C. Supraja, "Assessment of Electrokinetic Removal of Heavy Metals from Soils by Sequential Extraction Analysis,” Journal of Hazardous Materials, Vol. 84, No. 2, 2001, pp. 279-296. http://dx.doi.org/10.1016/S0304-3894(01)00237-0

[12] C. M. Zvinowanda, J. O. Okonkwo, P. N. Shabalala and N. M. Agyei, “A Novel Adsorbent for Heavy Metal Remediation in Aqueous Environment," International Journal of Environmental Science and Technology, Vol. 6, No. 3, 2009, pp. 425-434. http://dx.doi.org/10.1007/BF03326081

[13] M. Minamisawa, H. Minamisawa, S. Yoshida and N. Taka, "Adsorption Behavior of Heavy Metals on Biomaterials," Journal of Agricultural and Food Chemistry, Vol. 52, No. 18, 2004, pp. 5606-5611. http://dx.doi.org/10.1021/jf0496402

[14] S. E. Bailey, T. J. Olin, R. M. Bricka and D. D. Adrian, "A Review of Potentially Low-Cost Sorbents for Heavy Metals,” Water Resources, Vol. 33, No. 11, 1999, pp 24692479. http://dx.doi.org/10.1016/S0043-1354(98)00475-8

[15] J. Acharya, J. N. Sahu, B. K. Sahoo, C. R. Mohanty and B. C. Meikap, "Removal of Chromium (VI) from Wastewater by Activated Carbon Developed from Tamarind Wood Activated with Zinc Chloride," Chemical Engineering Journal, Vol. 150, No. 1, 2009, pp. 25-39. http://dx.doi.org/10.1016/j.cej.2008.11.035

[16] L. Khezami and R. Capart, "Removal of Chromium (VI) from Aqueous Solution by Activated Carbons: Kinetic and Equilibrium Studies," Journal of Hazardous Materials, Vol. 123, No. 1-3, 2005, pp. 223-231.

[17] J. C. Igwe, A. A. Abia and C. A. Ibeh, “Adsorption Kinetics and Intraparticulate Diffusivities of $\mathrm{Hg}$, $\mathrm{As}$, and $\mathrm{Pb}$ Ions on Ummodified and Thiolated Coconut Fiber," International Journal of Environmental Science and Technology, Vol. 5, No. 1, 2008, pp. 83-92. http://dx.doi.org/10.1007/BF03326000

[18] L. Agwaramgbo, E. Agwaramgbo, C. Mercadel, S. Edwards and E. Buckles, "Lead Remediation of Contaminated Water by Charcoal, LA Red Clay, Spinach, and Ustard Green,” Journal of Environmental Protection, Vol. 2, No. 9, 2011, pp. 1240-1244. http://dx.doi.org/10.4236/jep.2011.29142

[19] L. Agwaramgbo, N. Lathan, S. Edwards and S. Nunez, "Assessing Lead Removal from Contaminated Water Using Solid Biomaterials," Journal of Environmental Protection, Vol. 4, No. 7, 2013, pp. 741-745.

[20] N. Lathan, S. Edwards, C. Thomas and L. Agwaramgbo, "Comparative Study of Lead Removal by Extracts of Spi- 
nach, Coffee, and Tea," Journal of Environmental Protection, Vol. 4, No. 3, 2013, pp. 250-257. http://dx.doi.org/10.4236/jep.2013.43029

[21] L. Agwaramgbo, C. Thomas, C. Grays, J. Small and T. Young, "An Evaluation of Edible Plant Extracts for the Phytoremediarion of Lead Contaminated Water," Journal of Environmental Protection, Vol. 3, No. 8, 2012, pp. 722-730. http://dx.doi.org/10.4236/jep.2012.38086

[22] L. M. Mataka, E. M. T. Henry, W. R. L. Masamba and S. M. Sajidu, "Lead Remediation of Contaminated Water Using Moringa Stenopetala and Moringa Oleifera Seed Powder," International Journal of Environmental Science and Technology, Vol. 3, No. 2, 2006, pp. 131-139. http://dx.doi.org/10.1007/BF03325916

[23] G. Vankatesan and U. Senthilnathan, "Adsorption Batch Studies on the Removal of Cadmium Using Wood of Derris Indica Based Activated Carbon,” Research Journal of Chemistry and Environment, Vol. 17, No. 5, 2013, pp. 19-24.

[24] R. Menhage-Bena, H. Kazemian, M. Ghazi-Khansari, M. Hosseini and S. J. Shahtaheri, "Evaluation of of Some Natural Zeolites and Their Relevant Synthetic Types of Sor- bents for Removal of Arsenic from Drinking Water," Iranian Journal of Public Health, Vol. 33, No. 1, 2004, pp. 36-44.

[25] P. Stathi, K. Litina, D. Gournis, T. S. Giannopoulos and Y. Deligiannakis, "Physicochemical Study of Novel Organoclay as Heavy Metal Ion Adsorbents for Environmental Remediation,” Journal of Colloid and Interface Science, Vol. 316, No. 2, 2007, pp. 298-309.

[26] W.-Y. Shi, H.-B. Shao, H. Li, M.-A. Shao and S. Du, "Progress in the Remediation of Hazardous Heavy-Metal Polluted Soils by Natural Zeolite," Journal of Hazardous Materials, Vol. 170, No. 1, 2009, pp. 1-6. http://dx.doi.org/10.1016/j.jhazmat.2009.04.097

[27] E. Erden, N. Karapinar and R. Donat, "The Removal of Heavy Metal Cations by Natural Zeolites,” Journal of Colloid and Interface Science, Vol. 280, No. 2, 2004, pp. 309-314. http://dx.doi.org/10.1016/j.jcis.2004.08.028

[28] M. Aliabadi, K. Morshedzadeh and H. Soheyli, "Removal of Hexavalent Chromium from Aqueous Solution by Lignocellulosic Solid Wastes," International Journal of Environmental Science and Technology, Vol. 3, No. 3, 2006, pp. 321-325. http://dx.doi.org/10.1007/BF03325940 